\title{
Bergesen's Way Forward For World-System Theory After Gunder Frank
}

Sing C. Chew

Helmholtz Centre for Environmental Research-UFZ

Leipzig, Germany

sing.chew@ufz.de

Gunder Frank's ReOrienting the $19^{\text {th }}$ Century, published posthumously, was based on a long-term project of an evolving five-thousand year old world system undertaken in partnership with Barry Gills in the early 1990s (Frank 1990,1991, 1994; Frank and Gills 1992, 1993). This endeavor of Frank and Gills also produced a theoretically infused world system history of the making of the "modern" world. Frank's ReOrient: Global Economy in the Asian Age $(R G E A)^{1}$ was the first monograph of this theoretically informed world system history, and ReOrienting the $19^{\text {th }}$ Century (R19C) was the continuation volume. The latter, the topic of this symposium, despite being unfinished, resumes the argument of ReOrient: Global Economy in the Asian Age.

ReOrient: Global Economy in the Asian Age questioned (theoretically and historically) the manner we have interpreted long-term social change, and especially, our common understanding of the timing of the rise of the European domination of the world economy/system (the 1500 divide), and therefore, the specific region that was the dominant power of the world system at the particular historical conjuncture. ReOrienting the $19^{\text {th }}$ Century further buttressed this line of argument that the periodization of European dominance, as has been commonly accepted, needed even further revisions.

With these two volumes, Frank not only challenged the contemporary understanding (theoretically and historically) of the making of the "modern" world, but as well, the writings of his colleagues (such as Wallerstein, Arrighi, Amin, etc.) in worldsystems analysis, and even his own contributions to world-systems analysis prior to the early 1990s. Following Frank's typical critical iconoclastic stance, even Fernand Braudel was not spared (Frank 1994; Chew and Lauderdale 2010). Despite Gunder's numerous pleas, not too many in world-systems analysis pursued his demand for reorientation theoretically and historically in the rethinking of world history. In spite of this silence, in 1995, a core group of scholars from various disciplines, including Frank, convened in Lund (Sweden) to discuss the evolution of the world system/world-systems (Denemark et al. 2000). The product of the discussions was to engage and write world system history along a trans-disciplinary approach. It is best summed up by the title of the first volume of the group's collective research: World System History: The Social Science of LongTerm Change. Following this, numerous other world system history accounts of the making of the "modern" world were published (see, for example, Chase-Dunn and Hall 1997; Modelski and Thompson 1996; Chew 2001, 2007, 2008; Chase-Dunn and Anderson 2005; Gills and Thompson 2006; Modelski 2003; Modelski, Devezas, and

${ }^{1}$ For a critical review of $R G E A$, see the contributions of Arrighi, Amin, and Wallerstein in Review vol. 22, no. 3, 1999.

This work is licensed under a Creative Commons Attribution 4.0 United States License. Journal of World-Systems Research, Volume 21, Number 1, Pages 162-173, ISSN 1076-156X 
Thompson 2007). In this regard, Gunder Frank's monographs ( $R G E A$ and $R 19 C$ ) can be viewed as products of the World System History Group, and these two volumes should be considered as his last and lasting contributions to world system history.

\section{Bergesen's Way Forward: Forget History, Long Live Empiricism!}

Bergesen's article for consideration in this symposium, World-System Theory After Andre Gunder Frank, proposes to use some of the deliberations of Frank and Gills' conceptualization of the five thousand year-old world system as the way forward for world-system theory. His starting point, ontologically and epistemologically, is that we accept an "objective, non-theoretically constructed, facts-defined world, or global economy, to which can then be applied and evaluated the PEWS or any other model... rather than trying to explain the object (world-economy)" that "is fused with its theoretical explanation" (Bergesen 2015). Some might find this dictum welcoming, while others might not. I suspect even Gunder Frank might have difficulty making this shift, for in $R 19 C$ he wrote: "Not surprisingly, the further back we go through history, the scarcer and less reliable become the hard and especially quantitative data. Beyond these "natural" or "scientific" limitations, we run into essentially ideological ones. The selection of data to research and publish, and especially of those not to examine, is largely a function of the interests of the chronicler or researcher" (2014: 75). For those of us who are trying to re-think world history, it has always been an exercise of utilizing a history infused theory and a theory infused history to explain world development, hence the phrase, world system history. Notwithstanding this minor objection, let's proceed to consider the other elements of Bergesen's proposals.

\section{Bergesen's First Proposal}

Bergesen's going forward plan recommends dropping the concept of capitalism as a mode of production underlining the world-economy when dealing with the post-1500s global changes, and to realize the theoretical utility of his "world-system based globology approach." He joins Gunder Frank (1991) in dismissing the utility of the capitalist mode of production framework in understanding and explaining long-term change. Bergesen's argument, based on an ontological understanding of what is capitalism by definition, is rather straightforward. Because world-systems theory's level of analysis is the worldeconomy or world economy, and the capitalist mode of production theoretically belongs to the national level defined by worker-owner social relations guaranteed by a national state, "capitalism, as a mode of production, remains a societal/national entity"; he suggests that there is an issue in terms of translation - utilizing a concept that is based at the national level and employing it at the global level, though as he has correctly suggests, it has not prevented Lenin and Hobson from doing so. This "theoretical error" of Lenin and Hobson that starts from national accumulation, and then leads to the export of capital for further accumulation (exemplified by imperialism as the final stage of capitalism) on the world scale has to be dropped, according to Bergesen, if we intend to undertake a world-system level analysis. What Bergesen has done is accept the position

taken by Lenin as the only theory on the circuit of capital accumulation. The work of the 
late Rosa Luxemburg (1968), a contemporary of Lenin and Trotsky, offers us a much different formulation of the nature of the capitalist mode of production. Her theoretical edifice starts from the position that the circuit of capital accumulation involves different geographic zones/groups (that are capitalist, non-capitalist, protocapitalist, etc.), which capital absorbs/includes in its accumulation process. Hence, for Luxemburg capital accumulation has been a world-scale process since its inception, and not necessarily one starting from national accumulation and then the export of capital (globally) in the form of imperialism for global accumulation. ${ }^{2}$

Whereas Bergesen utilizes ontological and epistemological assertions to dismiss the world-system as having a capitalist mode of production in the post-1500 era, Frank's (1991) dismissal of using capitalism as a mode of production to understand the evolution of the world system is based mostly on his fervent insistence that the only "correct" route to understand long-term change or system transition is a world systemic analysis based on history and theory. In Frank's case, his declaration that feudalism, capitalism, and socialism are transitional ideological modes that has put blinders on our eyes, and thus has prevented us from really understanding and explaining the course of world history, is based on an examination of the historical processes of global history, and whether the characteristics of capitalism existed prior to 1500-hence, his 'continuity thesis.' Frank's rejection was historically based, and not derived from ontological and epistemological shifts of the sort Bergesen has proposed for world-system theory after Frank. Is Frank successful in convincing us to discount the need to use, in his terms, these ideological modes and myths that have imprisoned our world-system/world system analyses? $R G E A$ and $R 19 C$ are supposed to provide the historical information-theoretical reformulations to substantiate his claims.

\section{Bergesen's Second Proposal}

Frank's $R G E A$ and $R 19 C$ propose that we consider seriously analyzing the trading patterns and networks in terms of volumes of trade flows at the world system level in order to understand the course of world development, and to distinguish the economic and financial trends according to the different regions of the world economy. Because of his demand that everything has to be considered at the world level, bilateral trading flows do not capture the socioeconomic historical reality of what really happened in world history. A historical multilateral trading pattern analysis would be more precise in determining the relative dominance of the world system, and therefore, in socioeconomic and political terms, the real hegemonic region of the world system that is not ideologically derived and mythically reinforced. Frank's new 'mode of analysis' continues to mirror his previous mode of analysis, pre- and post- early $1990 \mathrm{~s}$, by focusing still on the "exchange" moment of the circulation of capital instead of directing his gaze more on the "production" and the "consumption" moments of the capital accumulation

\footnotetext{
${ }^{2}$ See Wallerstein (1980) for a theoretical-historical twist of Lenin's accumulation thesis within the perspective of world-systems analysis.
} 
circuit that world-systems analysis $\grave{a}$ la Wallerstein has done much to explain. ${ }^{3}$ This is very clear in $R G E A$ and $R 19 C$, and especially in $R G E A$.

Bergesen, following Frank, suggests that world-system theory drop the coreperiphery relational economic form of analysis and shift to a multilateral structural model of trade triangles based on positional placements (location) in the matrix. Added to this change should be a political economic dimension so that control and power can then be brought into the picture. This will better serve us to understand the relationship between the dominant region/power and the dominated in terms of economic resources that are derived by the dominant. According to Bergesen, this is how Frank in $R 19 C$ has been able to explain Britain's position in Frank's revised dating of British hegemony in the late $19^{\text {th }}$ century. In both $R G E A$ and $R 19 C$, Frank's argument was to deny it was Britain's indigenous assets and forces that led to Europe's domination of the world economy-a widely-accepted position that Frank sought to dismiss. ${ }^{4}$ To do this, it is understandable that Frank has to rely on external factors and the world system level model to dismiss what he has deemed a Eurocentric explanation for European domination of the world economy. A theory-sensitized search for the historical information was mounted, collected, and marshaled quite convincingly for this dismissal in $R 19 C$. I am sure there are, and will be, critiques on the periodization, the data, and other historical information that have been presented by Frank, besides his lack of sensitivity to the role of indigenous ideas and knowledge that precipitated Britain's and Europe's rise to global dominance.

Notwithstanding these critiques, which one can either treat as minor or even dismiss, the important contribution of Frank is that he is trying to offer an alternate explanation of past historical moments in world development and the historical processes that have produced such a course of world history. Bergesen (2015), however, proposes the opposite: that we should just research multilateral trade structures, and that we should take a "radical departure from present efforts to map properties of the historical moment, or moments past, or speculate upon moments to come"-all of which he considers no longer very helpful for our world-systems enterprise. He characterizes current worldsystems practioners' efforts to explain the dynamics of the world economy as similar to a dog chasing its tail; "each turn of a dog chasing its tail is somewhat different from the previous one, and research effort can either be spent noting the unique properties of each turn, or identifying the finite properties of the dog and the tail that generate these endless turns." He proposes doing the latter. His proposal, therefore, underscores the "continuity thesis" (see Chapter 3 of $R 19 C$ for a historical application of this) that Frank and Gills have been arguing for since the early 1990s (see, for example, Gills 1996; Frank 1998): there is more continuity in terms of socioeconomic patterns and structures, especially the latter, than disruptions or dissipations of structures. In this sense, for example, there has been no break starting from 1500 onwards.

Bergesen's proposal, notwithstanding his disavowal of the need to consider historical moments and historically informed theory, presents us with the same concerns I have raised in the past with Frank's continuity argument (Chew 2002). Historical

\footnotetext{
${ }^{3}$ See the critique of Brenner (1977) of early world-systems analysis of Frank and Wallerstein. Whereas Wallerstein's later works looking at production commodity chains, households, and antisystemic movements have addressed Brenner's various criticisms, Frank has never fully responded to them, other than in his joint work with his late wife, Marta Fuentes on anti-systemic movements.

${ }^{4}$ See for ex., the works of Goldstone (2002), Mann (1986), Jones (1981), etc.
} 
moments of ruptures and dissipations no longer are considered important to explain the course of world history, or for that matter, world system history. By declaring the theoretical irrelevance of the mode of production to explain the development pattern and the nature of change, Gunder Frank had diminished any specific contingent factors or processes that underline system transformation (and the change that follows) which the mode of production form of analysis had been able to furnish and distinguish. In other words, for Gunder Frank world development is distinguished by the economic cycles of expansion and contraction, center-periphery relations, hegemonic rivalry, etc. There is no specificity of a transformation for a particular historical epoch: "the rules of the game are not much altered so much as the position of the players" (1996: 44). Frank again repeated this in a draft version ${ }^{5}$ of ReOrienting the $19^{\text {th }}$ Century, where he stated:

The argument herein as it was in ReOrient is that only a GLOBAL framework of analysis is necessary, not only of course to do a-or a political economic-history of the WORLD, but to have any hope of seeing where any of its regional, sectoral, or processual PARTS fit into the general scheme of things. Secondly IF we do that, we will discover that historical CONTINUITY has been far more important than any and all its dis-continuities. The perception of a major new departure in 1500 , and even of one in 1800 which allegedly spell a discontinuous break in world history, is substantially [mis] informed by a Eurocentric vantage point. Once we abandon this Eurocentrism and adopt a more globally holistic world or even pan Eurasian perspective, dis-continuity is replaced by far more continuity Or the other way around? Once we look upon the whole world more holistically, historical continuity looms much larger, especially in Asia. Indeed, the very "Rise of the West" itself appears derived from this global historical continuity (2005:59)

There is therefore a tendency to stress the continuity of the evolution of the world system instead of looking for or being aware of break points in world history whereby contingent factors and circumstances conduced system transformations. Even though I believe that the mode of production form of analysis is analytically fruitless, Gunder's proposed solution characterizes world history as an endless cycle of repetitions of political, economic, and social processes, and does not distinguish the significance of historical epochs and the specificity of the systems transformation that preceded them. In other words, world history is devoid of critical ruptures and specificities. His proposed theoretical framework has the tendency to lead us down this path.

\section{Beyond Bergesen: Theoretical Issues with ReOrienting the $19^{\text {th }}$ Century}

By stressing the continuity of the structures and processes of the world system and the irrelevance of the mode of production analysis to explain development pattern and the

\footnotetext{
${ }^{5}$ This citation, derived from the draft manuscript that was unfinished, in my opinion provides us with a more virulent defense of the continuity thesis cited above than what was published in the final version. The equivalent citation appears in the published volume on page 43.
} 
direction of social change, Frank has flattened world history and made it devoid of critical ruptures and specificities, as I have stated previously. For Gunder Frank, longterm social change over world history is depicted by long economic cycles of expansion and contraction (that he has not elaborated on why they occur), core-periphery relations, and hegemonic rivalry. There is no specificity of a transformation for a particular historical epoch as he has put it, just different players at the table (Frank 1996: 44).

Can additional theoretical scaffolding be erected to overcome this issue (and it is not a return to the mode of production form of analysis that I also find analytically fruitless as world history has revealed), and additional alterations be added to firm up the foundation of his five-thousand-year world system history approach? What should be included? More than two decades ago, I had made a remark to Gunder that in spite of his attempt to write a world history that is humanocentric, which is to be applauded, there was a major dimension that was missing in his overall framework. It was ecology, for at that time I was writing an ecological world system history (Chew 2001). He had agreed then that it was a missing dimension, and one that is extremely important. In ReOrient the $19^{\text {th }}$ Century, he does try to address this issue of ecology by writing about ecological entropy that is created by the core in its ceaseless accumulation, and generating and dissipating the entropy to the periphery by its extraction and consumption of global natural resources.

With this entropy dissipation model placed within the multilateral trade system, Frank again sticks to his old "dependency" model whereby the core generates the problems globally, and it is the periphery that absorbs and suffers, though in this case, he shrouds it under the model of energy flows. Rather than seeing global system crisis as a result of a set of relations between global culture (characterized by a degree of hierarchical consumption) and Nature leading to critical conditions, Frank wants to place all the blame on the core for its excessive consumption with no responsibility placed on the rest of the world. In short, it is an anthropocentric form of analysis instead of an ecocentric one whereby it is the human community-of course with core and periphery having different degrees of responsibility-that generates the crisis. For Frank with his call for a humanocentric approach towards understanding world development and world history, he cannot move towards a position of the sort that I have called for (Chew 1997). Egalitarianism is not exclusively for the human species, but has to be for all species (Devall 1988; Naess 1984).

Furthermore, by emphasizing a humanocentric approach and utilizing an entropy dissipation model (to replace unequal exchange in core-periphery relations), Frank continues to account for all system crises as coming from the realm of social, political, and economic activities, thus underscoring 'the economy in command' dictum that he had so often depicted in his writings. He does not give leeway to the fact that there might be other independent/dependent factors such as ecological ruptures, surprising natural events, extreme weather shifts etc., that can affect the socio-technical-economic system and generate system crises. Perhaps, after all, it is "ecology in command" that has the final say in global crises (Dark Ages) and transformation (Chew 1997, 2007, 2008). 


\section{Crisis}

Given the above, for Frank, world development is a perpetual cycle of economic expansion and contraction. That is how he explained the final demise of Asia and the rise of Europe in the $19^{\text {th }}$ century. A "B-phase" of economic contraction was occurring in the world system and the economies of China, India, and Southeast Asia were experiencing economic distress, and Europe (like the newly industrialized economies of Asia in the late $20^{\text {th }}$ century) maximized economically on this period of economic contraction. Thus Asia's demise preceded Europe's rise.

If we are to understand the trajectory of world development and world history, such a flattened view of world history does not illuminate much. Frank, in his attempt to overcome certain breakpoints in world history, which he believed have been established as a result of the centric-ness (such as the 1500 break, as a result of Eurocentrism) of some analyses, does not address the issue of system crisis and transformation. As we know, all systems eventually will reach crisis conditions, and the effort is to maintain system equilibrium, which we know is especially difficult in systems that are organized on a hierarchical order with inequality as one of its basic features. The numerous theoretical and empirical works of Immanuel Wallerstein $(1988,1996,1998,2004)$ on the systemic crisis of a historical world system have addressed this issue precisely. Frank's model does not deal with system crisis and transformation; it is an endless cycle of system reproduction and perpetuation.

\section{Economic Stagnation and Crisis}

Social (world) system crisis means that the continued evolution of the world system faces obstacles, and that necessary structural changes/adjustments have to be made for systems reproduction to continue. These crisis phases become the key periods for our understanding of the dynamics of world system evolution and transition (long-term social change). Over world history, these crisis moments are rare. When they do occur, these phases are extremely impactful in terms of geographic coverage, and they extend over a long period in terms of socioeconomic and ecological recovery.

Conceptually, the factors and processes that trigger crises over the last five thousand years have not been worked out or well understood. That however has not prevented the identification of these economic stagnations or B-phases. With the plethora of positions on world system/s development, crises or B-phases have been proposed to cover different duration, and have different meanings for those working in this area. In addition to the Gills and Frank's model I have outlined in the previous pages, Modelski and Thompson (1996) and Wallerstein $(1974,1980)$ also comes to mind. According to each model, the duration of these downturn phases varies. Different durations ranging from 50 years to one thousand years in length have been suggested.

Leaving this difference in duration aside for the moment, there are also different views of what a B-phase is in relation to world system $/ \mathrm{s}$ reproduction. For Gills and Frank (1993), B-phases represent the cyclical tendency or rhythms that a world system goes through as it expands. In other words, a B-phase is a cyclical downturn of the world system within its rhythm of expansion and contraction, a structural process of the world system (Gills and Frank 2002: 159-160). They are recurrences of economic downturns. 
Along this reasoning, there is no notable difference between one B-phase and another. They are all economic downturns with no distinguishing characteristics depicting a specific era (conjuncture) of the world system, other than sharing similar tendencies such as hegemonic rivalries. Therefore, historical contingent circumstances/factors are not given much weight nor proffered to explain the genesis or resolution of the crisis.

Another view of a B-phase is quite different. For Wallerstein $(1974,1979,1980)$ for example, a specific B-phase is not only signifying an economic crisis period (price fluctuations, etc.), it also demarcates specific characteristics of system reorganization and consolidation, depending on the particular B-phase in question. In his explication of the origin and evolution of the modern world-system, the B-phase between AD1300-AD1450 has been analyzed as a reorganization of the social structure ("the crisis of feudalism") in order to overcome the crisis conditions (Wallerstein 1980:25); In contrast, the B-phase between $\mathrm{AD} 1600-\mathrm{AD} 1750$ is considered not as a "crisis in the system" but as "a period of consolidation" of social relations and structures with its respective specificities (Wallerstein 1980: 31). Thus, a specific B-phase crisis has certain triggers that trip the crisis. In the case of the B-phase between $\mathrm{AD} 1300-\mathrm{AD} 1450$, the particular triggers for the "crisis of feudalism" were a conjuncture of secular trends, immediate cyclical crisis, and climatological decline.

The apparent differences in just Frank and Gills' and Wallerstein's positions have implications for our understanding of the factors conditioning system crisis. If we consider a Wallersteinian B-phase, we need to note that it has some commonalities such as cyclical economic contraction trends (price changes, production losses, etc.) with other recurrent B-phases. In this case, Wallerstein's interpretation is similar to Gills and Frank's understanding of a B-phase. However, for Wallerstein, a specific B-phase might also be different from other B-phases, for it also has certain contingent particular characteristics (e.g., breakdown of feudal social relations, climate changes) of the epoch in question that condition the system crisis. Hence, the specific conjuncture and its contingent socioeconomic and political characteristics are included in an understanding of the precipitation and determination of the crisis or contraction. Given this direction, for Wallerstein the identification of common elements that condition crises recurring over world history needs to be combined with the conjunctural elements in order to understand the crisis. The attempt, therefore, is to straddle nomothetic and idiographic methodologies for an explanation of system crisis and transition.

Between these two viewpoints of B-phases, there are those that are closer or further away from the above two positions. Modelski and Thompson $(1996,2003)$ have suggested the recurrent nature of crisis and transitions over long cycles in the historical evolution of the world system. Agreeing with Gills and Frank on the dynamics of the world system since $3000 \mathrm{BC}$, according to them, the recurring crisis phases have been characterized by learning (technological, writing, information, etc.) innovations, political hegemonic struggles, population, urbanization, migrations, climate, and warfare. ${ }^{6}$ Unlike Frank (1992), Modelski and Thompson have identified both particular elements (technological innovation, information, writing, etc.) that underline a specific crisis phase, and common elements such as deurbanization, migration, population decreases, which permeate every system crisis phase. Beyond the widely agreed element of negative

\footnotetext{
${ }^{6}$ The identification of climate as an element in the crisis phase rests on the work of Thompson (2000, 2001).
} 
economic trends defining a B-phase, what we have are additional delineation of elements such as those that are specific (information, technological innovations, and writing), and other common elements (deurbanization, migration, climate, and population decreases) that all form the matrix circumscribing system crisis and transition. For Modelski and Thompson, system crises, therefore, are transition points of system adaptation and evolution.

In view of the state of discourse on long-term change over world history, we should also be aware of long-term structural crises-beyond a B-phase of contraction-that a historical world system experiences; what Modelski (2006) has called 'ages of reorganization' or what I have identified as Dark Ages (Chew 2007). Wallerstein's (1998, 2004; Hopkins and Wallerstein 1996) more recent works have also addressed this in terms of system maturation and transformation. These crises have also occurred in the past, and prior to the modern era have not been fully noted or understood. We do have some indications from historical accounts of social, political, and economic long-term downturn periods, and preliminary identification of the characteristic processes depicting these phases. Besides the above preliminary attempts to decipher recurrent patterns of social, economic, and political characteristics underlying the systemic crisis phases, there are very few idiographic efforts made to identify and explain the contingent factors, agents, and conditions that might have also played a part in engendering each specific system crisis phases. ${ }^{7}$ The latter task is even more challenging, especially in light of the available archaeological evidence for the premodern period.

Given the above, can we buttress the five-thousand year world system model of Frank and Gills further to overcome the lacunae I have identified in the previous section? I propose that we first accept the ontological statement that "Theory Is History"-a view that Gunder (1978:13) also shares-as we go about filling the lacunae. If this is the case, can we find specific periods in world history when there is a world system crisis from which we can derive generalized concepts, and at the same time, outline specific contingent factors and processes that lead to system transformation from these specific occasions? Indeed, these are the periods known as the Dark Ages in world history that I have described, though they are quite rare in world system history; in fact, about three such periods have occurred in the past five thousand years (Chew 2007). In view of this, system transformations whereby structural changes occur come quite infrequently (maybe Gunder is right on this; things do not change that often) and, perhaps, they are not cyclical in nature. These are the moments of structural ruptures and reconfiguration that the current world system may be experiencing (Chew 2008).

Our task therefore is to sketch out a theoretically generalized history of system crisis or Dark Ages, and within the limits of available historical information, identify contingent factors and agents that could have engendered each specific system crisis phase or Dark Age from the Bronze Age to the Iron Age of world history (Chew 2007, 2008). The end point would be a social science history of long-term change-i.e., a history of the evolution of the world system.

\footnotetext{
${ }^{7}$ For example, see Drews (1993) for the crisis of the Bronze Age of 1200 B.C. The more recent work of Eric Cline (2014) also covers this system crisis.
} 


\section{Conclusion}

Clearly, Andre Gunder Frank's view of world development and world history is quite refreshing, especially in light of current global transformations, and especially for those outside the core zones who are looking for alternate views of world development and world history. In an era of critical cultural and social debates on global issues that are often determined knowingly and unknowingly by dominant ideological frameworks such as Eurocentrism, nationalism, socialism, etc., Gunder Frank's type of scholarship will be sorely missed, in spite of some of the inadequacies that I identified. He was, I believe, a harbinger of truth as to what happened in the past and what could very likely occur in the future, not only in terms of world development, but as well in the world of academic scholarship. I conclude with the following, as he frequently did: A Luta Continua!

\section{References}

Brenner, Robert. 1977. "The Origins of Capitalist Development: A Critique of NeoSmithian Marxism." New Left Review (July-August): 25-72.

Chase-Dunn, Christopher and Thomas D. Hall. 1997. Rise and Demise: Comparing World-Systems. Boulder: Westview Press.

Chase-Dunn, Christopher and E. N. Anderson, eds. The Historical Evolution of WorldSystems. New York: Palgrave.

Chew, Sing C. 1997. "For Nature: Deep Greening World-Systems Analysis for the $21^{\text {st }}$ Century." Journal of World-Systems Research 3(3): 381-402.

------. 2001. World Ecological Degradation : Accumulation, Urbanization, and Deforestation. Lanham, MD: AltaMira Press/Rowman and Littlefield Publishers.

------. 2002. "Globalization, Dark Ages, and Ecological Degradation." Global Society 16 (4): 333-356.

------- 2007. The Recurring Dark Ages: Ecological Stress, Climate Changes and System Transformation. Lanham: AltaMira Press/Rowman and Littlefield Publishers.

------. 2008. Ecological Futures: What History Can Teach Us. Lanham MD: AltaMira Press/Rowman and Littlefield Publishers.

Cline, Eric H. 2014. 1177 B.C.: The Year Civilization Collapsed. Princeton, NJ: Princeton University Press.

Denemark, Robert, Jonathan Friedman, Barry K. Gills, and George Modelski, eds. 2000. World System History: The Social Science of Long-Term Change. London: Routledge.

Devall, Bill. 1988. Simple in Means, Rich in Ends. Salt Lake City, UT: Gibbs Smith.

Drews, R. 1993. The End of the Bronze Age. Princeton, NJ: Princeton University Press.

Frank, Andre Gunder. 1978. World Accumulation 1492-1789. New York: Monthly Review Press. 1991. "Transitional Ideological Modes: Feudalism, Capitalism, Socialism." Critique of Anthropology 11(2): 171-188. 1993. "Bronze Age World System Cycles." Current Anthropology 34(4): 383-429. 
1996 “The Underdevelopment of Development." Pp. 17-56 in Sing C. Chew and Robert Denemark, eds. The Underdevelopment of Development: Essays in Honor of Andre Gunder Frank. Thousand Oaks: Sage Publications.

------. 1998. ReOrient: Global Economy in the Asian Age. Berkeley: University of California Press.

------. 1993. The World System: Five Hundred Years or Five Thousand? London: Routledge.

------. 1994. "The World Economic System in Asia Before European Hegemony." The Historian 56(4): 259-276.

------. 2005. ReOrient The $19^{\text {th }}$ Century, Unpublished book manuscript.

------. 2014. ReOrienting the $19^{\text {th }}$ Century: Global Economy in the Continuing Asian Age. Boulder: Paradigm Publishers.

Frank, Andre Gunder and Gills, Barry K. 1992. "World System Cycles, Crises, and Hegemonial Shifts." Review 15(4): 621-688.

Gills, Barry K. 1996. "The Continuity Thes is in World Development." Pp. 226-245 in Sing C. Chew and Robert Denemark, eds. The Underdevelopment of Development. Thousand Oaks: Sage Publication.

Gills, Barry K. and Andre Gunder Frank. 2002. "A Structural Theory of the Five Thousand Year Old System." Pp. 151-176 in Sing C. Chew and David Knottnerus, eds. Structure, Culture, and History: Recent Issues in Social Theory. Lanham, MD: Rowman and Littlefield.

Gills, Barry K. and W.R. Thompson, eds. 2006. Globalization and Global History. London: Routledge.

Goldstone, Jack. 2002. "Efflorescences and Economic Growth in World History: Rethinking the 'Rise of the West' and the Industrial Revolution." Journal of World History 13 (Fall): 323-389.

Hopkins, Terrence K. and Immanuel Wallerstein. 1996. The Age of Transitions 19452025. London: Zed Books.

Jones, Eric. 1981. The European Miracle. Cambridge: Cambridge University Press.

Luxemburg, Rosa. 1968. The Accumulation of Capital. New York: Monthly Review Press.

Mann, Michael. 1986. The Sources of Social Power, Vol. 1. Cambridge: Cambridge University Press.

Modelski, George. 1999a. "Ancient World Cities 4000-1000B.C.: Center/Hinterland in the World System." Global Society 13(4): 383-392. 1999b. "Classical World Cities 1200B.C. to A.D. 1000: Facets of World System Evolution." Encyclopedia of Human Ecology. San Diego CA: Academic Press.

------. 2006. "Age of Reorganization: Self-organization in the World System." Nature and Culture 1(2): 205-227.

Modelski, George and Thompson, William R. 1996. Leading Sectors and World Powers. Columbia: University of South Carolina Press. 1999. "The Evolutionary Pulse of the World System: Hinterland Incursion and Migrations 4000 B.C. to A.D. 1500."Pp. 241-274 in Nick Kardulias, ed. World System Theory in Practice. Lanham, MD: Rowman and Littlefield. 
------. 2001. "Evolutionary Pulsations in the World System."Pp. 177-196 in Sing Chew and David Knottnerus, eds. Structure, Culture, and History. Lanham, MD: Rowman and Littlefield.

Modelski, George, Tessaleno Devezas, and William Thompson, eds. 2007. Globalization as Evolutionary Process: Modeling Global Change. New York: Routledge.

Naess, Arne. 1984. Ecology, Community, and Lifestyle. Cambridge: Cambridge University Press.

Thompson, William R. 2000. "C-Waves, Center-Hinterland Contact and Regime Change in the Ancient Near East: Early Impacts of Globalization." Paper presented at the International Studies Association Annual Meeting, Los Angeles, California.

------. 2001. "Trade Pulsations, Collapse, and Reorientation in the Ancient World." Paper presented ta the International Studies Association Annual Meeting, Chicago, Illinois.

Wallerstein, Immanuel. 1974. The Modern World-System Vol. 1 New York: Academic Press.

------. 1976. "A World-Systems Perspective on the Social Sciences." British Journal of Sociology 27(2): 342-352. 1979. "Kondratieff Up or Down." Review 2(4): 663-73.

------. 1980. "Imperialism and Development." Pp. 13-23 in Albert Bergesen, ed. Studies of the Modern World-System. New York: Academic Press.

------. 1981. The Modern World-System Vol. 2 New York: Academic Press.

-----. 1988. "Typology of Crises in the World-System." Review 11(4): 581-598.

------. 1989. The Modern World-System Vol. 3 New York: Academic Press.

------. 1998. Utopistics. New York: New Press.

------. 2004 World-Systems Analysis. Durham: Duke University Press. 